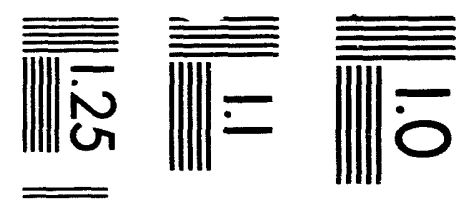

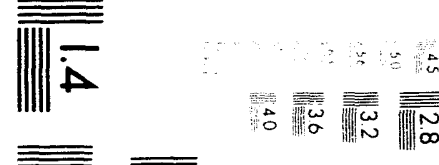

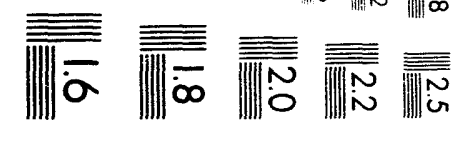



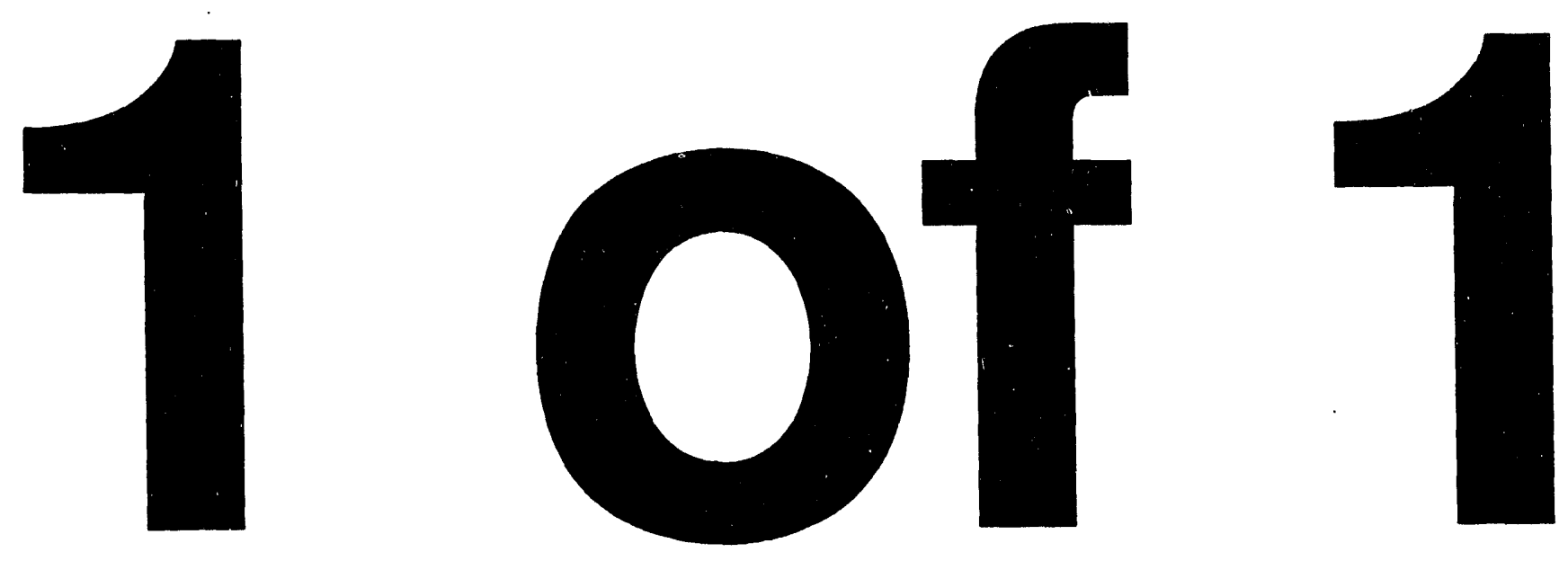


\title{
Advanced Steady-State Operating Scenarios
}

\author{
W.M. Nevins, R.H. Bulmer, \\ L.D. Pearlstein, S.W. Haney, \\ and J. Manickam
}

December 2, 1993

This is an informal report intended primarily for internal or limited external jistribution. The opinions and conclusions stated are those of the author and may Tr may not be those of the Laboratory.

Work performed under the auspices of the U.S. Department of Energy by the lawrence Livermore National Laboratory under Contract W-7405-Eng-48.

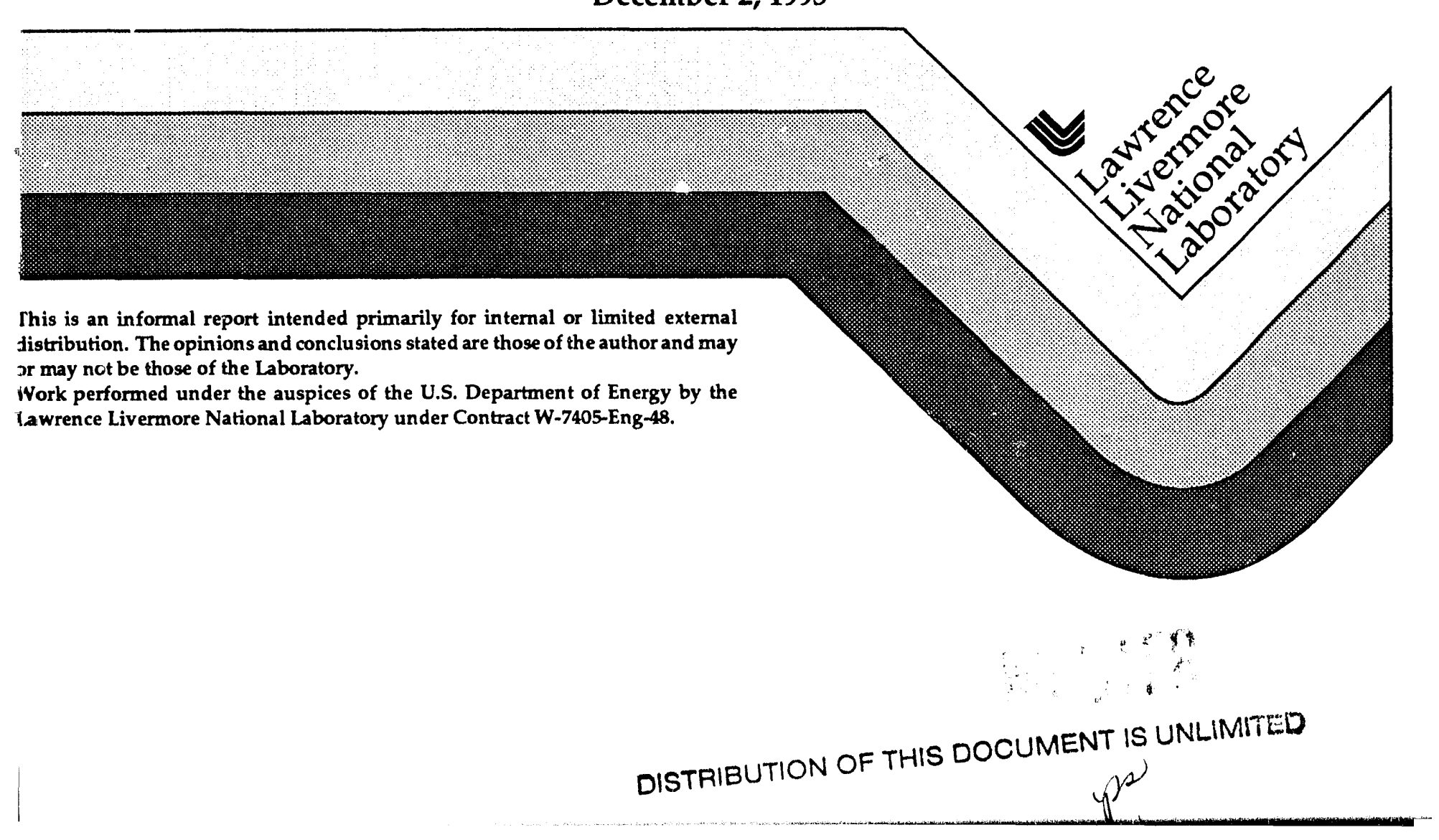




\section{DISCLAIMER}

This document was prepared as an account of work sponsored by an agency of the United States Government. Neither the United States Government nor the University of California nor any of th employees, makes any warranty, express or implied, or assumes any legal liability or responsibility for the uracy, completeness, or usefulness of any information, apparatus, product, or process disclosed, or represent, that its use would not infringe privately owned rights. Reference herein to any specific commercial products, process, or service by trade name, trademark, manufacturer, or otherwise, does not necessarily constitute or imply its endorsement, recommendation, or favoring by the United States Government or the Universit y of California. The views and opinions of authors expressed herein do not necessarily state or reflect those of the United States Government or the University of California, and shall not be used for advertising or product endorsement purposes.

This report has been reproduced directly from the best available copy.

Available to DOE and DOE contractors from the Office of Scientific and Technical Information P.O. Box 62, Oak Ridge, TN 37831

Prices available from (615) 576-8401, FTS 626.8401

Available to the public from the

National Technical Information Service

US. Department of Commerce

5285 Port Royal Rd.,

Springfield, VA 22161 


\title{
Advanced Steady-State Operating Scenarios
}

\author{
W.M. Nevins, R.H. Bulmer, L.D. Pearlstein, and S.W. Haney \\ Lawrence Livermore National Laboratory \\ Livermore, CA USA \\ J. Manickam \\ Princeton Plasma Physics Laboratory \\ Princeton, NJ USA
}

The goal for advanced steady-state operation in ITER should be to demonstrate the operation of the plasma core for a steady-state fusion reactor. To accomplish this we must develop steady-state operating scenarios at high beta $\left[\beta_{n}{ }^{*} \approx .05\right.$, where $\beta_{n}{ }^{*} \equiv<\beta^{2}>1 / 2 /\left(I_{p} / a B_{0}\right)$, with $I_{p}$ in $\Lambda_{i} A$, a in meters, and $B_{0}$ in Tesla] for high fusion power density, low auxiliary power requirements $\left(Q_{C D} \geq 25\right.$, where $Q_{C D} \equiv P_{\text {fusion }} / P_{C D}$ and $P_{C D}$ is the power required for sustaining the plasma current) for low recirculating power requirements, and at moderate safety factor $\left(q_{\psi} \leq 4.5\right)$ to minimize the cost for the tokamak core of a steady-state demonstration power reactor based on the operating modes demonstrated in ITER.

The key to achieving steady-state operation at high fusion power in ITER will be the development of operating scenarios with very high bootstrap current fractions $\left(f_{B S} \geq 90 \%\right)$ in which the radial profile of the bootstrap current density is well aligned with that of the total plasma current density, and for which the MHD $\beta$-limit exceeds $\beta_{n}{ }^{*}=0.05 \mathrm{~T}-\mathrm{m} / \mathrm{MA}$. Such advanced steady-state operating scenarios like have been developed in connection with the TPX project. ${ }^{1}$ Similar operation was proposed for the Steady State Tokamak Reactor. ${ }^{2}$ These operating scenarios are based on the PEP mode observed in JET ${ }^{3}$ and other tokamaks. ${ }^{4}$ A key feature of this operating mode is a non-monotonic current

\footnotetext{
${ }^{1}$ W.M. Nevins et al., Mission and Design of the Tokamak Physics Experiment/Steady-State Adoanced Tokamak (TPX/SSAT), Plasma Physics and Controlled Nuclear Fusion Research 1992, 14th Conference Proceedings, Würzburg, Germany, 1992 (IAEA, Vienna, 1993) Paper IAEA-CN-56/F$1-5$.

${ }^{2}$ Y. Seki et al., Concept Study of the Steady State Tokamak Reactor (SSTR), JAERI-M 91-081 (Japan Atomic Energy Research Institute, June 1991). See $\$ 4.4$ by T. Ozeki.

${ }^{3}$ P. Kupscus, et al., High Thermonuclear Yield on JET by Combining Enhanced Plasma Performance of ICRH-Heated, Pellet-Peaked Density Profiles with H-mode Confinement, Proc. of the 18th European Conference on Controlled Fusion and Plasma Physics Research (Berlin, 1991) I, 1.

${ }^{4}$ T.C. Simonen et al, Recent DIII-D Results, Plasma Physics and Controlled Nuclear Fusion Research 1992, 14th Conference Proceedings, Würzburg, Germany, 1992 (IAEA, Vienna, 1993) Paper IAEA-CN-56/A-1-2; Equipe Tore Supra, Recent Results of the TORE SUPRA Tokamak;
} 
profile, such that the q-profile has a minimum off axis. This leads to a region of reversed shear between the minimum in the q-profile and the magnetic axis, which is in the second stable regime to high-n ballooning modes. In addition, the Rebut-Lallia-Watkins ${ }^{5}$ and other transport models transport models ${ }^{6}$ predict excellent confinement in the region of reversed shear. The expected strong reduction in transport is observed in the reversed shear region in JET PEP-mode discharges.

We are in the process of developing such operating modes for ITER. In §1 we propose two advanced steady-state operating points; a preliminary operating point that was the basis for the MHD studies reported in $\S 2$, and a second operating point that has been optimized based on our studies to date. In $\S 2$ we present calculations indicating that the initial operating point is stable to MHD ballooning and low- $n$ kink modes (with a conducting wall at $r=1.25 \mathrm{a}$ ) up to $\beta_{n}{ }^{*} \approx 6 \times 10^{-2} \mathrm{~T}-\mathrm{m} / \mathrm{MA}$. In $\S 3$ we present a free-boundary MHD equilibrium, and show that advanced steady-state operating modes are compatible with the ITER poloidal field system and divertor.

\section{Proposed Operating Points}

The steady-state plasma performance that might be expected in ITER in a reversed-shear operating mode is illustrated in Table 1 . The initial operating point was generated by taking the temperature, density, and plasma geometry for a typical ignited operating point. The density profile is assumed to be only moderately peaked ( $n_{e o} /\left\langle n_{e}\right\rangle \approx 1.6$ ); while the temperature is assumed to be strongly peaked ( $T_{e o} /\left\langle T_{e}\right\rangle=2.3$ ) consistent with the theoretical requirements for bootstrap current alignment and MHD stability (see §2), and with experience in inverted shear operation in both JET and DIII-D. The total plasma current was chosen to give a high bootstrap current fraction (using a bootstrap current computed self-consistently with the assumed density, temperature, and current profiles), while still leaving $\beta_{\mathrm{n}}{ }^{*}$ within the range expected to be stable to MHD modes in reversed-shear operation. The energy confinement time is then determined from the stored energy, the current drive power required to support the difference between the total plasma current and the bootstrap current, and the computed fusion power (assuming a helium ash fraction of $20 \%$ ).

The improved operating point was obtained using the same peakedness in the density and temperature profiles, and the more favorably shaped plasma (compatible with the ITER divertor and poloidal field systems) described in $\S 3$.

Plasma Physics and Controlled Nuclear Fusion Research 1992, 14th Conference Proceedings, Würzburg, Germany, 1992 (IAEA, Vienna, 1993) Paper IAEA-CN-56/A-1-4.

5P.H. Rebut et al., Plasma Physics and Controlled Nuclear Fusion Research 1992, 13thConference Proceedings, Washgton, D.C., 1990 (IAEA, Vienna, 1991) 2, 191.

${ }^{6}$ W.M. Tang, private communication. 
The optimizing systems code, SUPERCODE? , was used to find an optimum operating point subject to constraints on the bootstrap current fraction $\left(f_{B S} \geq 90 \%\right.$ ), fusion power ( $\left.P_{\text {fusion }} \leq 2 \mathrm{GW}\right), \beta_{n}\left(\beta_{n} \geq .05\right)$, and $q_{\psi} \cdot\left(3.5 \leq q_{\psi} \leq 4.5\right)$ appropriate for demonstrating advanced steady-state operating modes in ITER.

Table 1. ITER Advanced Steady-State ITER Points

\begin{tabular}{|c|c|c|}
\hline Parameter & $\begin{array}{c}\text { Initial } \\
\text { Operating Point }\end{array}$ & $\begin{array}{c}\text { Optimized } \\
\text { Operating Point }\end{array}$ \\
\hline$P_{\text {fusion }} / P_{C D}(M W)$ & $2200 / 30$ & $2000 / 50$ \\
\hline$Q_{C D}$ & 73 & 40 \\
\hline $\mathrm{R}_{0} / \mathrm{a} \quad(\mathrm{m})$ & $8.1 / 3.0$ & $8.46 / 2.68$ \\
\hline$\kappa / \delta$ & $1.53 / 0.23$ & $1.71 / 0.44$ \\
\hline $\mathrm{B}_{\mathrm{O}}$ & 6.0 & 4.34 \\
\hline$q_{\psi}$ & 5.6 & 4.22 \\
\hline$I_{p} \quad(M A)$ & 13 & 12.22 \\
\hline$f_{B S}$ & $98 \%$ & 0.91 \\
\hline$\beta_{n} / \beta_{n}{ }^{*}(m-T / M A)$ & $4.44 \% / 5.96 \%$ & $5.0 \% / 6.7 \%$ \\
\hline$<\mathrm{n}_{\mathrm{e}}>\left(\times 10^{20} \mathrm{~m}^{-3}\right)$ & 1.4 & 1.25 \\
\hline$\left\langle\mathrm{T}_{\mathrm{e}}\right\rangle_{\mathrm{n}} \quad(\mathrm{keV})$ & 12 & 10 \\
\hline$\tau_{E} \quad$ (seconds) & 5.7 & 2.64 \\
\hline$\tau_{\mathrm{E}} / \tau_{\text {ITER-P }}$ & 4.4 & 2.59 \\
\hline
\end{tabular}

It is clear from Table 1 that key issues for these advanced operating modes in ITER are the MHD $\beta$-limit, the alignment of the bootstrap current profile with a total current profile that is MHD stable at the assumed $\beta$, and energy confinement. The first two issues (MHD $\beta$-limit and bootstrap current alignment) are dealt with in $\$ 2$ below. A detailed assessment of energy confinement will require 1-1/2 dimensional transport modeling to better define

${ }^{7}$ S.W. Haney et al, Fusion Technology 21, 1749 (1992). 
the expected range of density and temperature profiles, and to quantify the confinement improvement that can be expected due to the magnetic shear reversal in the plasma core.

We note that the energy confinement enhancement required for the optimized operating point has been substantially reduced. This is, in part, due to increased heating power (now $50 \mathrm{MW}$ ) and to the increased plasma reactivity due to a lower helium ash fraction (down from $20 \%$ for the initial operating point to $12 \%$ for the optimized operating point). This corresponds to the conservatve assumption that the effective confinement time for the helium ash, $\tau_{\alpha}{ }^{*}$, that is 14.1 times larger than the energy confinement time, $\tau_{\mathrm{E}}$.

Fig. 1. P and q-profiles vs. "radius"

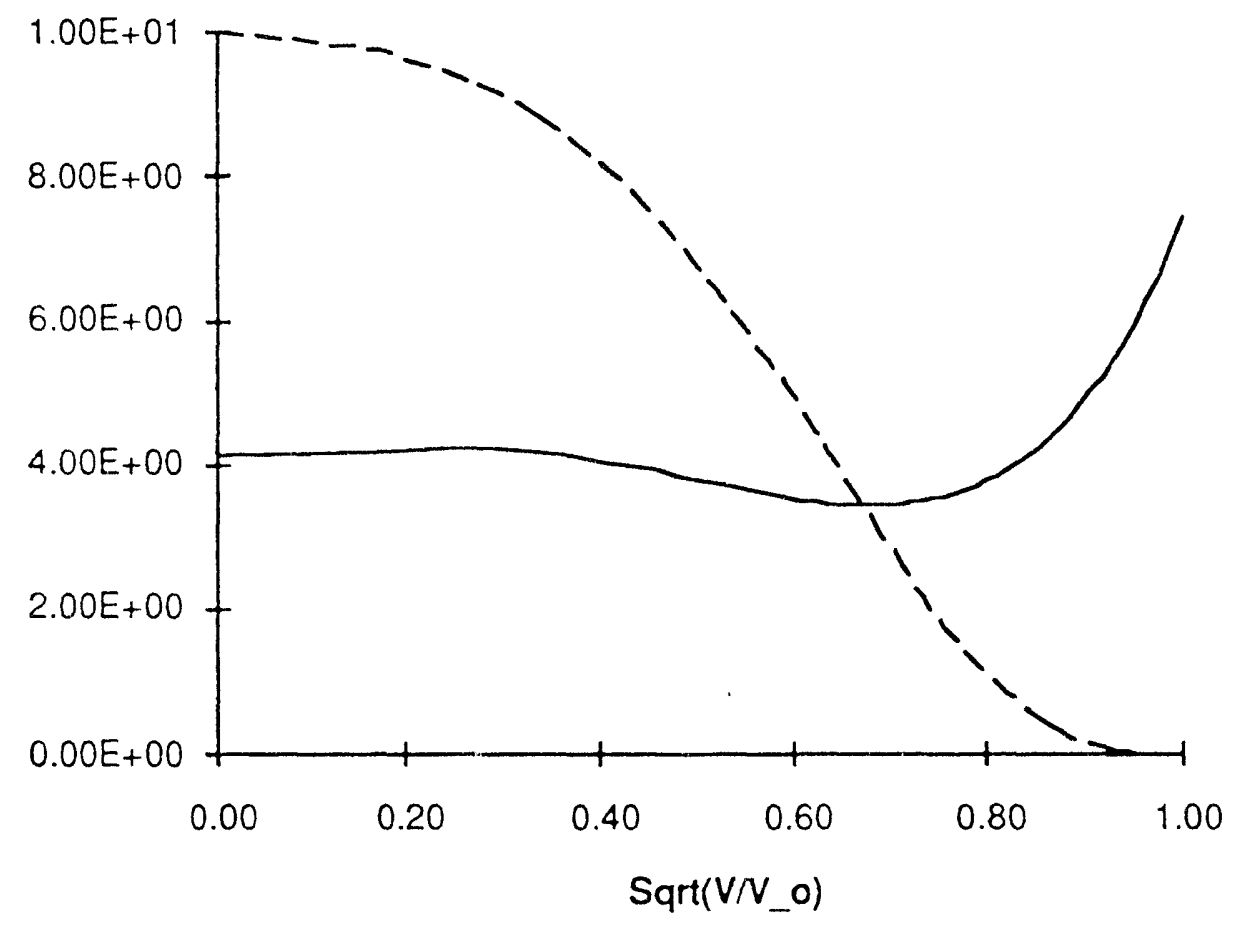

\section{MHD Stability}

Recent work by C. Kessel, J. Manickam, and others in support of the TPX design ${ }^{8}$ has demonstrated that tokamak discharges in this reversed shear mode with well aligned bootstrap current profiles can be stable to both MHD kink and ballooning modes for $\beta \leq 0.06 \times \mathrm{I}_{\mathrm{p}} / \mathrm{aB}_{\mathrm{O}} \mathrm{T}-\mathrm{m} / \mathrm{MA}$. This demonstration motivated

\footnotetext{
${ }^{8}$ S.Jardin et al, Advanced Plasma Configurations, in TPX Physics Design Description, G.H. Nelson, Editor (93-930325-PPPL/GNelson-01, March, 1993).
} 
the present study in which these reversed shear operating modes are adapted to ITER. For the purposes of this study we assumed an up-down symmetric plasma (due to limitations of the available tools) with a major radius $R_{0}=8.1 \mathrm{~m}$, a minor radius $a=3.0 \mathrm{~m}$, an elongation $\kappa=1.53$, a triangularity $\delta=0.23$, and a toroidal magnetic field $B_{0}=6 T$ at $R=8.1 \mathrm{~m}$. The pressure and $q$-profiles corresponding to the Initial Operating Point proposed in Table 1 are shown in Figure 1.

Using the PEST MHD stability code we found that these profiles are stable to both ballooning modes and low-n kink modes up to $\beta_{n}=4.44 \%$ with a conducting wall at $r \approx 1.25 \mathrm{a}$. Since the pressure profile is strongly peaked, this corresponds to a $\beta^{*}=5.96 \%$ [where $\beta^{*}=<\beta^{2}>1 / 2 /\left(\mathrm{I}_{\mathrm{p}} / \mathrm{a} \mathrm{B}_{0}\right)$ is a better measure of the averaged reactivity of the plasma]. Note the magnetic shear reversal over the inner $3 / 4$ of the plasma radius, and the strongly peaked pressure profile. The bootstrap current profile (as computed using the Harris model ${ }^{9}$ and total current profiles consistent with the q-profile shown in Fig. 1 (and with MHD stability up to $\beta_{\mathrm{n}}=4.44 \%$ ) are shown in Fig. 2 .

Fig. 2. Profiles of $J_{\text {bootstrap }}$ and $J_{\text {total }}$ vs. "radius".

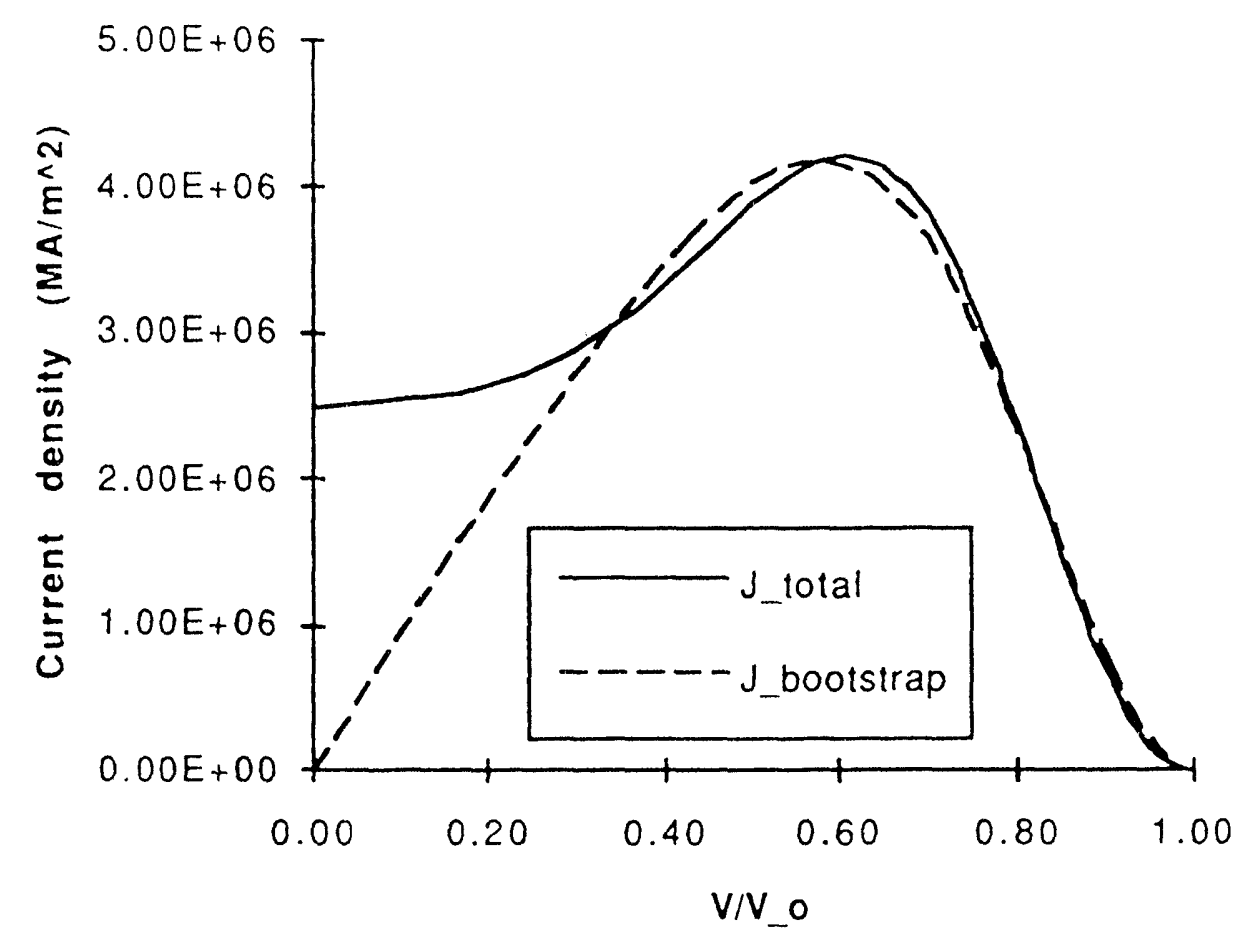

The bootstrap current is seen to be very well aligned with the total current profile. Less than $1 \mathrm{MA}$ of non-inductively driven seed current will be required

\footnotetext{
${ }^{9}$ see, e.g., G.R. Harris, Comparisons of Different Bootstrap Current Calculations, EUR-CEA FC 1436 (1991). Submitted for publication in Nuclear Fusion.
} 
from the ITER heating and current drive systems to support this plasma in steady-state. We have not yet studied the MHD stability properties of the Optimized Operating Point proposed in Table 1.

Stability to kink modes at the proposed reversed shear operating point depends on the presence of a conducting wall at $r=1.25 \mathrm{a}$. The ITER blanket and shield will fill this role. However, it may be necessary to insure that the plasma rotates in order to prevent mode locking, and subsequent growth of low- $n$ MHD modes on the resistive time scale of the wall. Tangential neutral beam injection is an effective means of applying a torque to the plasma and driving plasma rotation. The resulting plasma rotation can be estimated by assuming that the toroidal momentum confinement time is similar to the energy confinement time as found in studies of toroidal momentum confinement prepared for the ITER CDA. ${ }^{10}$ Assuming injection of $50 \mathrm{MW}$ of $500 \mathrm{keV}$ neutral beams aimed at a tangency radius of $R_{\text {tang }} \approx 4.0 \mathrm{~m}$, we estimate a toroidal plasma rotation velocity of $3 \times 10^{4} \mathrm{~m} / \mathrm{sec}$, and a rotation frequency of $3.6 \times 10^{3} \mathrm{rad} / \mathrm{sec}$. Further studies will be required to determine how much plasma rotation is required, and the best method of providing this rotation.

\section{Compatibility with ITER Poloidal Field System and Divertor}

The pressure and q-profiles similar to those developed in the MHD study described in $\$ 2$ were used in the free-boundary MHD code TEQ to study the compatibility between the proposed operating point and the ITER poloidal field system and divertor (it was not possible to input the identical profiles because TEQ assumes a different family of pressure and current profiles than those used by the PEST MHD code). The resulting equilibrium is shown in Figure 3.

We found that it was easier to satisfy the shape constraints (maintaining proximity between the plasma and the ICRH antenna, maintaining the plasma elongation, and mapping the scrape-off-layer plasma into the divertor chamber) if we allowed the plasma triangularity to increase to $\langle\delta 95 \%\rangle=0.44$ (as shown in Fig. 3). This increase in the triangularity would be expected to improve the stability against ballooning modes. We tested this single-null equilibrium for ballooning stability, and verified that the ballooning mode stability limit increased to $\beta_{n} \leq 4.95 \%$. The single null equilbrium has not been tested for low $-n$ MHD stability.

The configuration shown is a minimum current state (the sum over all poloidal field coils of the square of the current density has been minimized). This flux state can be achieved with an inductive current ramp-up and a pre-

\footnotetext{
${ }^{10}$ D.E. Post et al., ITER Physics, (ITER Documentation Series No. 21, IAEA, Vienna, 1991). See $\S 2.1 .5$.
} 
charge that is within the capability of the ITER transformer. All of the poloidal field coil currents are well below their limits. Hence, we conclude that the proposed advanced steady-state operating mode is compatible with the ITER poloidal field system.

Finally, we note that the scrape-off-layer plasma does map in to the ITER divertor chamber. This can be seen in Fig. 2, which shows both the separatrix and the flux surface $5 \mathrm{~cm}$ from the separatrix at the outboard mid plane (shown by the dashed curve). Note also that the plasma density and total heating power are similar to those in TTER ignited operation, while $\mathrm{q}_{\psi}$ is substantially larger $\left(q_{\psi} \approx 5.6\right.$ for this steady-state operating mode vs. $q_{\psi} \approx 3.0$ for ignited ITER operation). Hence, we conclude that the proposed advanced steady-state operating mode is compatible with the ITER divertor.

\section{Summary}

There are substantial difficulties in achieving advanced steady-state operating modes-the high $\beta_{n}$ and strongly peaked pressure profiles are only possible in the presence of the inverted current profile that we propose to sustain with the neoclassical bootstrap effect. This current profile depends, in turn, on the presence of the plasma pressure. We have shown that self-consistent operating points exist that have high bootstrap fraction and are stable at the required $\beta$. It remains to determine time-dependent scenarios for achieving these operating points in tokamak reactor plasmas. We note that a substantial physics R\&D effort is presently underway in support of advanced steady-state tokamak operation. i or example, this is a key goal of the JT-60U program in Japan, and that the goal of the TPX program in the US is to develop means of achieving advanced steady-state discharges and maintaining them in steady-state. We can expect substantial progress advanced, steady-state tokamak operation between now and the beginning of ITER operation in 2007. 
ITER Reverse Shear Op Mode \#93051

E

$N$

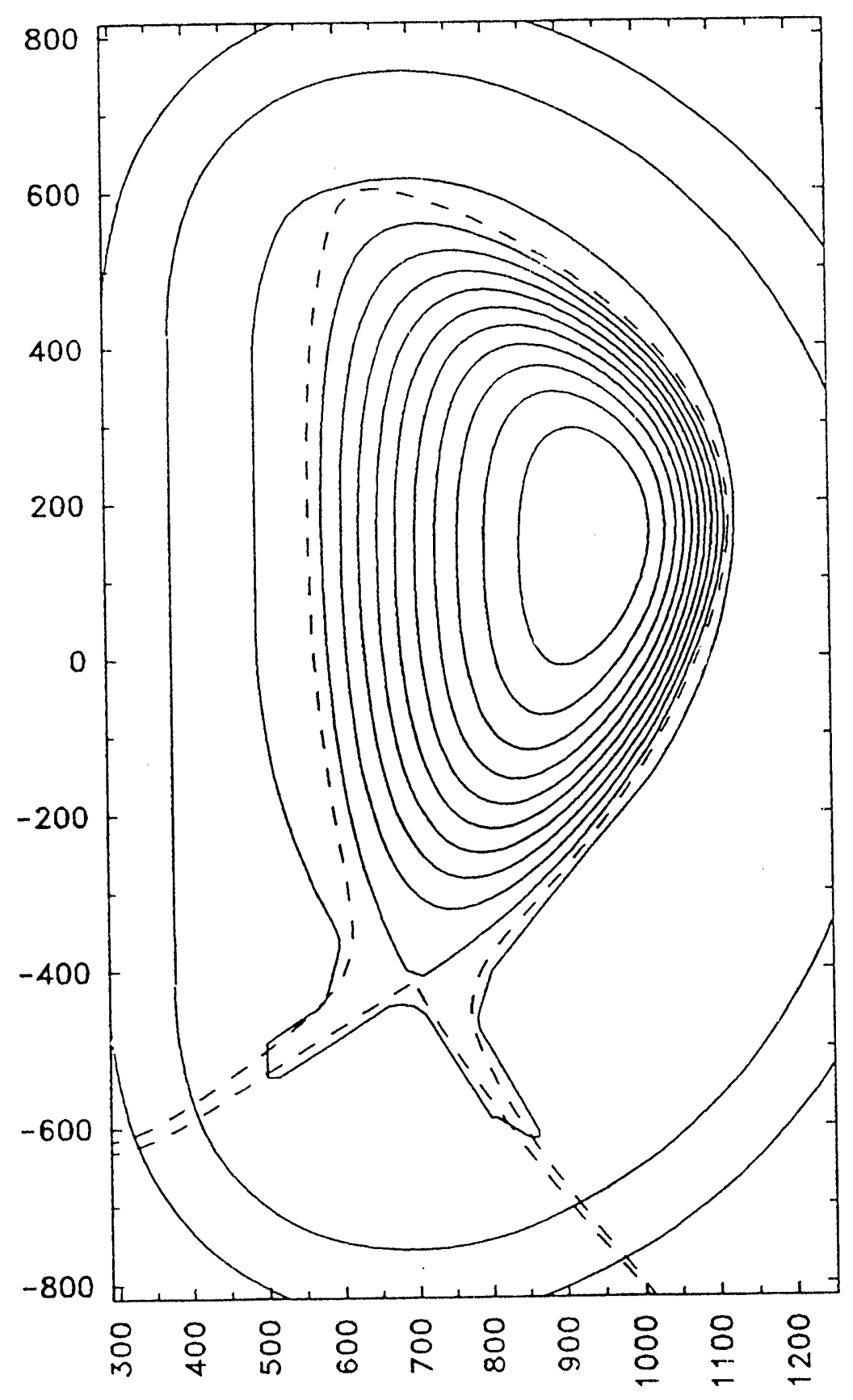



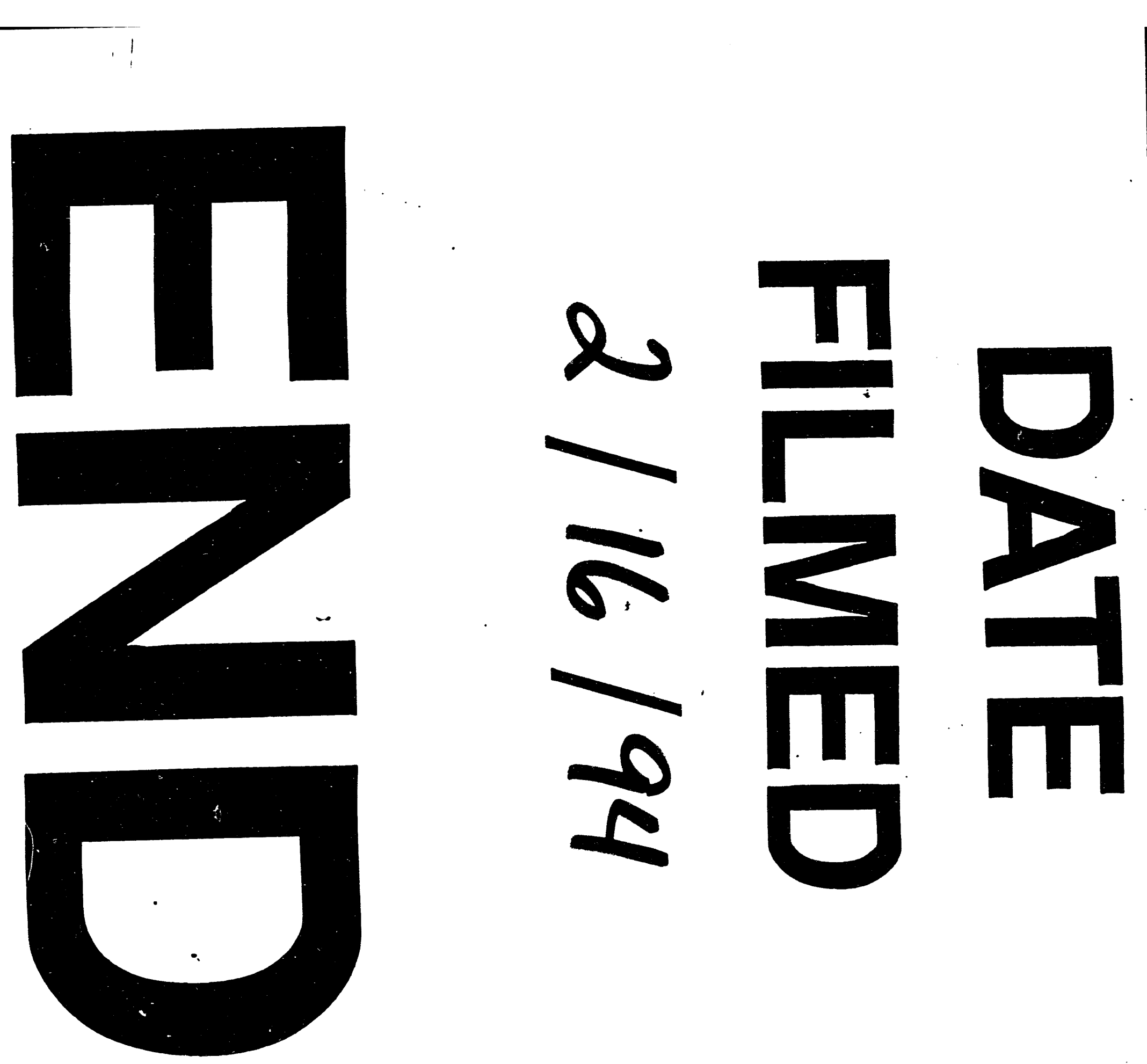